\title{
FRONT SLOPE STABILITY OF THE ICELANDIC-TYPE BERM BREAKWATER
}

\author{
Sigurdur Sigurdarson ${ }^{1}$ and Jentsje van der Meer ${ }^{2}$
}

\begin{abstract}
The front slope stability of the berm breakwater has often been assessed through the recession parameter, Rec. Icelandic-type berm breakwaters are designed with very large rock, where recession under design conditions is very limited and where the erosion is in the same order of magnitude as the rock damage parameter, $S_{d}$. Recent tests of front slope stability of the Icelandic-type berm breakwater became available with very accurate measurements of recession Rec as well as damage $\mathrm{S}_{\mathrm{d}}$. Damage values are compared with the Van der Meer formulae for rock slopes and appear to agree fairly well. A more refined definition of recession has been developed. Instead of measuring the recession on top of the berm it is proposed to measure it either as the mean or the maximum horizontal recession on the front slope of the berm. The initial recession values have been compared with earlier work on recession and a main conclusion is that the effect of the wave height is far more important than the wave period. Therefore it is proposed to consider only the stability number and a prediction formula has been given. Finally, the paper discusses two alternative designs which can lower the risk of not getting the predicted and expected armour stone yield in a breakwater project. These are a gentler seaward slope of 1:2.5 and replacement of large class I rock by cubes.
\end{abstract}

\section{INTRODUCTION}

The stable berm breakwater concept has been in development over the past 25 years and nearly 40 such structures have been constructed worldwide over a wide range of wave climates, water depths and tidal conditions and structure geometry. The paper is focussed on hardly reshaping and very stable berm breakwaters, called here the Icelandic-type berm breakwater. It discusses three main points for design, focusing on the front slope stability. These points are a more precise description of reshaping, recession and damage; an analysis of damage and recession, including comparison; and a description of two alternatives in case the very large rock class appears not to be available in practice.

The term berm breakwater is used for a rather wide range of structures. When first introduced in the early eighties it was used for a wide, porous mass of quarry stone constructed as a horizontal berm with a steep seaward profile that was intended to allow for movement of stones under wave action. Under design storm conditions, and even for lower wave heights, this would cause consolidation and nesting of stones leading to full reshaping of the whole berm. The reshaped profile shows a milder slope around the still water level. This area has been investigated by Van der Meer (1988) and has resulted in a procedure in the BREAKWAT program, where the full reshaped profile is calculated as function of hydraulic conditions and structure geometry. It should be noted that BREAKWAT can only be used for stability numbers $\mathrm{H}_{\mathrm{s}} / \Delta \mathrm{D}_{\mathrm{n} 50}>2.7$ and that

\footnotetext{
${ }^{1}$ IceBreak Consulting Engineers, Smararimi 46, IS-112, Reykjavik, ICELAND, sigurdur.sig@simnet.is

${ }^{2}$ Van der Meer Consulting BV, P.O. Box 423, 8440 AK, Heerenveen, NL, jm@vandermeerconsulting.nl
} 
these kind of berm breakwaters should actually not be designed for values larger than 3 .

In Iceland berm breakwaters developed into more stable structures where the larger armour stone were sorted out and placed at the most exposed locations within the breakwater cross section, which results in a berm built up of several narrowly graded armour classes. As a result of the more narrowly graded armour classes, the porosity of the armour layer increases, increasing its permeability, which eventually results in increased stability and less reshaping of the berm. Eventually this development has lead to the introduction of the Icelandic-type berm breakwater with very low stability numbers and hardly any reshaping.

PIANC (2003) classifies berm breakwaters in three categories based on the stability parameters $\mathrm{H}_{\mathrm{o}}=\mathrm{H}_{\mathrm{s}} / \Delta \mathrm{D}_{\mathrm{n} 50}$ and $\mathrm{H}_{\mathrm{o}} \mathrm{T}_{\mathrm{om}}=\mathrm{T}_{\mathrm{m}}\left(\mathrm{g} / \mathrm{D}_{50}\right)^{0.5}$, see Table 1 .

\begin{tabular}{|c|c|c|}
\hline Type of breakwater & $\mathrm{H}_{0}$ & $\mathrm{H}_{0} \mathrm{~T}_{\mathrm{om}}$ \\
\hline Statically stable non-reshaped berm breakwater & $<1.5-2$ & $<20-40$ \\
\hline Statically stable reshaped berm breakwater & $1.5-2.7$ & $40-70$ \\
\hline Dynamically stable reshaped berm breakwater & $>2.7$ & $>70$ \\
\hline
\end{tabular}

The stable berm breakwater falls into either of the categories Statically stable non-reshaped berm breakwater or Statically stable reshaped berm breakwater. This paper will focus on the first category with limited recession and small stability numbers, the Icelandic-type berm breakwater.

For statically stable non-reshaped and reshaped berm breakwaters, the profile reshaping is limited and the actual area of interest is the erosion of the berm, or the so-called recession, Rec, often defined as in Figure 1. Note that Figure 1 is a principal sketch and not a result of real measurements. Certainly if the rock becomes very large and the recession very limited it is not possible to measure the recession accurately with one or a few profiles.

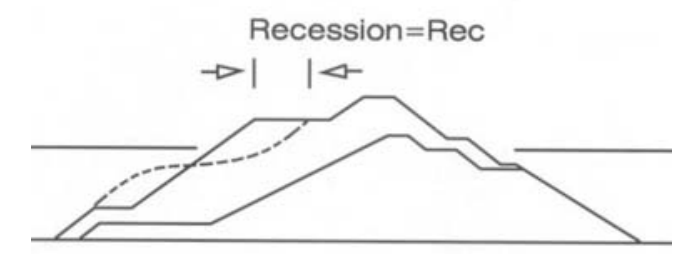

Figure 1. Principal sketch of recession of the berm on a berm breakwater.

PIANC (2003) RECESSION DATA FOR BERM BREAKWATERS

PIANC (2003) presented recession data of many research projects, mainly with traditional reshaping berm breakwaters as well as partly Icelandic-type berm breakwaters, see Figure 2. Most of the data represent a recession larger than 
$5^{*} \mathrm{D}_{\mathrm{n} 50}$ and a stability parameter $\mathrm{H}_{\mathrm{o}} \mathrm{T}_{\mathrm{om}}$ larger than 70 . A large scatter is present due to various influences. Some of them would be the definition of wave height (at the toe or more at deep water), placement of rock (dumped or carefully placed), way of measuring recession, seaward slope angle, etc.

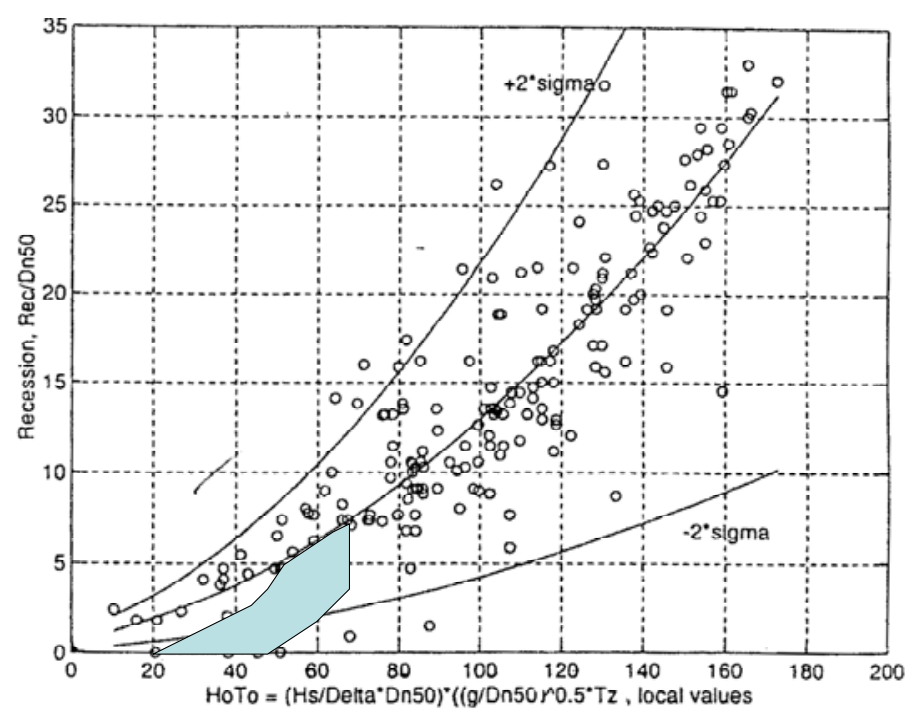

Figure 2. Recession data from PIANC (2003), including the data in Sigurdarson et al. (2008) on stable Icelandic-type berm breakwaters.

As stated above most of the PIANC (2003) data represented large recession and high stability numbers, $\mathrm{H}_{\mathrm{o}} \mathrm{T}_{\mathrm{om}}$. Focusing only on Icelandic-type berm breakwaters changes the area of interest. With the limits of $\mathrm{H}_{0} \mathrm{~T}_{\mathrm{om}}<70$ and not more than 7-8 stones removed across the berm $\left(\operatorname{Rec} / \mathrm{D}_{\mathrm{n} 50}<8\right)$ leaves only the data of the lower left corner of Figure 2. In this region there are data points which do not show any recession for $\mathrm{H}_{\mathrm{o}} \mathrm{T}_{\mathrm{om}}=40-50$ and others that show recession to be 7 or 8 stone wide. Also, there are data points showing recession of 2 stone wide for $\mathrm{H}_{0} \mathrm{~T}_{\mathrm{om}}$ values of only 10 . The only conclusion is that the data given in PIANC (2003) is not able to give any reliable design guideline for the Icelandic-type berm breakwater. More well-defined data is required to give such guidelines.

Sigurdarson et al (2008) defined requirements for reliable data representing the Icelandic-type berm breakwater and indentified three data sets which fulfilled these requirements: MAST II (1996 and 1997), Myhra (2005) and Sveinbjörnsson (2008). The recession data covers the area shown in Fig. 2 and is really focussed around small recession. They found that the best fit for the recession data was obtained using the parameter $\mathrm{H}_{\mathrm{o}} \mathrm{T}_{\mathrm{op}}$, which includes the peak period, $T_{p}$, instead of the mean period, $T_{m}$. But the difference with using only the stability number $\mathrm{H}_{\mathrm{o}}=\mathrm{H}_{\mathrm{s}} / \Delta \mathrm{D}_{\mathrm{n} 50}$, so not considering the wave period, was not 
large. Based on that data Sigurdarson et al. (2008) derived the following formula that provided a reasonable fit to the data shown in Figure 3:

with:

$$
\mathrm{Rec} / \mathrm{D}_{\mathrm{n} 50}=0.032\left(\mathrm{H}_{0} \mathrm{~T}_{0 \mathrm{p}}-\mathrm{Sc}\right)^{1.5}
$$

and:

$$
\mathrm{Rec} / \mathrm{D}_{\mathrm{n} 50}=0 \text { for } \mathrm{H}_{0} \mathrm{~T}_{0 \mathrm{p}}<\mathrm{Sc}
$$

$$
\mu(\mathrm{Sc})=35 \text { and } \sigma(\mathrm{Sc})=5 \text { and } \mathrm{H}_{0} \mathrm{~T}_{0 \mathrm{p}}<70
$$

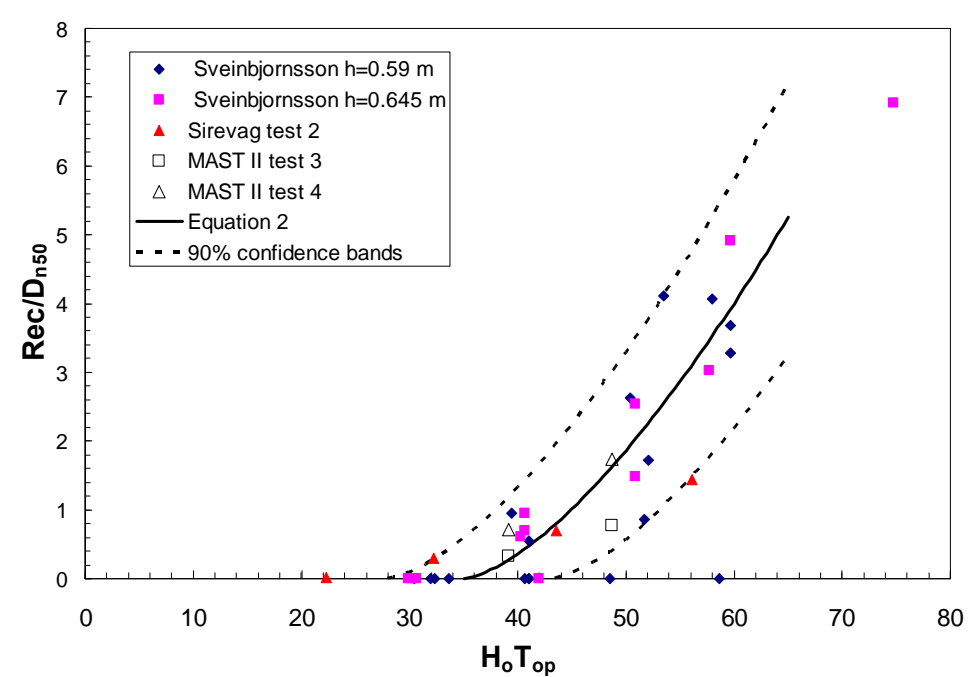

Figure 3. Recession data for an Icelandic-type berm breakwater, using the peak period $T_{p}$ and showing the recession formula (2) with $90 \%$ confidence band as presented by Sigurdarson et al. (2008).

\section{NEW AND ACCURATE DATA SET INCLUDING ANALYSIS}

\section{Optimized definition of recession}

A statically stable design of an Icelandic-type berm breakwater has been tested in a wave flume at HR Wallingford, where the behaviour from the start of moving of the first stones, up to a few times an overload condition, was measured very precisely.

At the start of damage the recession of the berm profile varies considerably along the profile. But when the damage gets larger and the berm really reshapes into the well-know S-profile, the recession becomes more. In that case it is sufficient to measure only a few profiles, average them and measure the recession, the horizontal retreat of the berm, given in nominal diameter of the armour stone protecting the berm, $\mathrm{D}_{\mathrm{n} 50}$. This has often been done in berm breakwater research, also for the less reshaping Icelandic-type berm breakwater. 
In the research at HR Wallingford a very accurate laser profiler has been used and according to the method in Van der Meer (1988) ten profiles have been averaged to give a good description of the behaviour of the structure.

Figure 4 shows an example of damage development of the averaged 10 profiles from the pre-test condition, through the full sequence of testing. Some profile or damage development starts, ending in a little reshaping at the end of the test series. Figure 5 shows on the other hand the individual ten profiles after two times the design condition. It is clear that the scatter between the different profiles is considerably larger than the average profile development over the full test sequence.

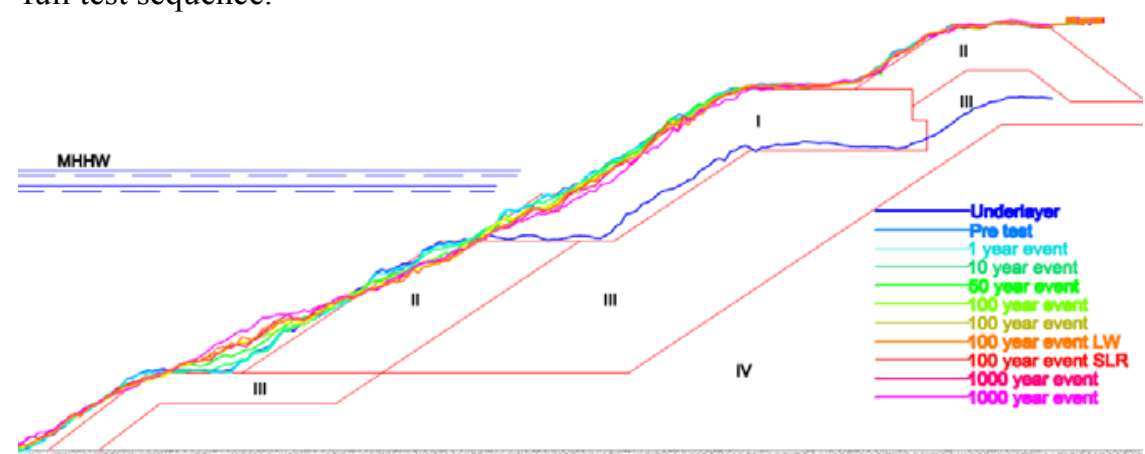

Figure 4. Development of profiles of an Icelandic-type berm breakwater under increasing wave conditions, measured with a laser profiler; each profile is the average of 10 individual profiles.

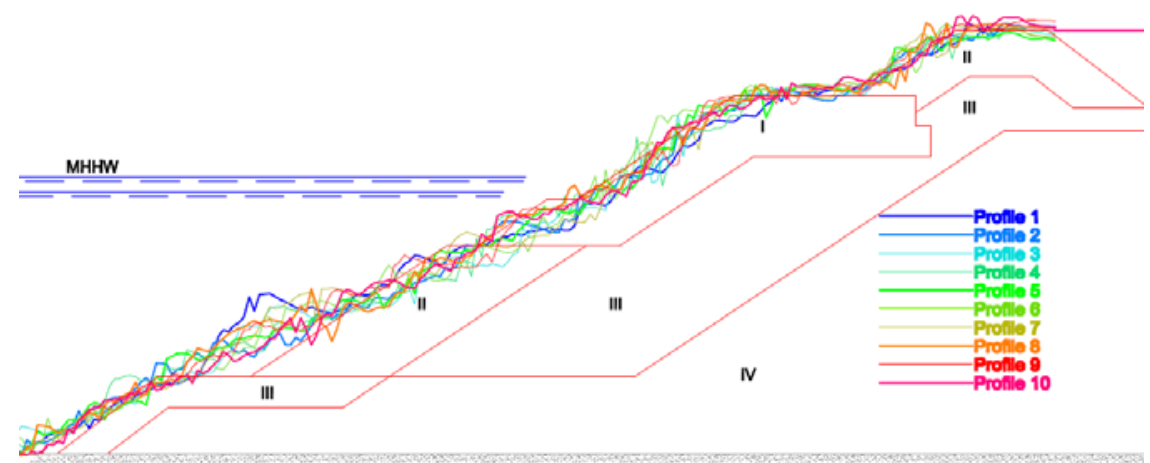

Figure 5. Ten individual profiles of the same Icelandic-type berm breakwater measured with a laser profiler after two times the design event, showing the large scatter of individual profiles.

The recession of a berm breakwater is usually defined as shown in Figure 1, that is the horizontal recession on top of the berm. This may be alright for structures that experience considerable recession but not so good for structures experiencing less recession. The damage or displacement of stones usually starts at around the still water level and then proceeds upward. For limited damage, as for the Icelandic-type berm breakwater, the damage might not have 
proceeded up to the top of the berm where the recession usually is measured. Another practical issue is that the recession on top the berm is not easy to define. The front slope and top of the berm of the Icelandic-type berm breakwater is covered with large stones and when these are profiled, the profile rarely shows a sharp intersection between the front slope and top of berm.

Therefore, it was necessary to modify the definition of recession to take note of profile development on the full slope from top of the berm down to low water level, not only on top of the berm. The recession is taken as the horizontal difference between the as-built profile of the Class I armour and the profile recorded after the test, see Fig. 6. Two recession parameters have been proposed. The maximum recession distance, $\mathrm{Rec}_{\max }$, is the greatest recession measured on any individual profile, and the average recession distance, $\operatorname{Rec}_{\mathrm{av}}$, is the recession of the average profile averaged between low water level and top of the berm.

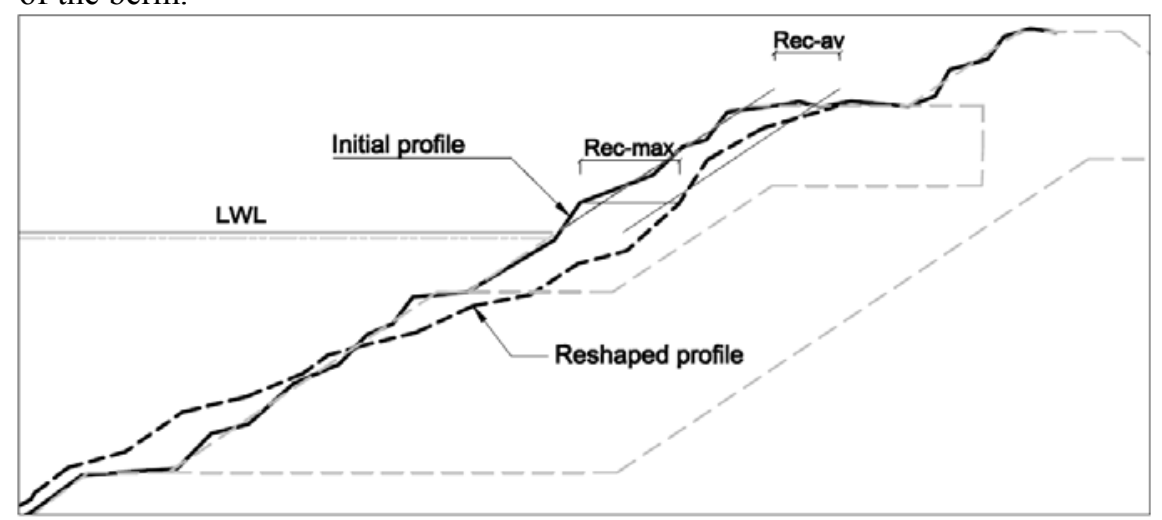

Figure 6 . The modified definition of a berm recession.

\section{The dataset}

The seaward slope of the berm had a slope of 1:1.5. The berm itself is very porous with large rock in the whole berm. According to Van der Meer (1988) this would give a notional permeability factor of around $\mathrm{P}=0.55-0.6$. The erosion area $A_{e}$ can also be found from the profile, which results in the damage parameter $S_{d}=A_{e} / D_{n 50}{ }^{2}$. It is, therefore, interesting to make a comparison between damage measured for the Icelandic-type berm breakwater and damage calculated by stability formulae for rock slopes.

Details of wave conditions, damage and recession for the three tests are given in Table 2. Design conditions for about 100-years return period are reached for stability numbers of $\mathrm{H}_{\mathrm{s}} / \Delta \mathrm{D}_{\mathrm{n} 50}=1.5-1.7$. Overload conditions are reached $\mathrm{H}_{\mathrm{s}} / \Delta \mathrm{D}_{\mathrm{n} 50}=2.0-2.4$. Note that in many tests the wave steepness was quite low and therefore the wave period fairly long. This results in fairly large $\mathrm{H}_{\mathrm{o}} \mathrm{T}_{\mathrm{om}}$ and $\mathrm{H}_{\mathrm{o}} \mathrm{T}_{\mathrm{op}}$ values. Maximum recession in Tests 1 and 2 amount to about $\operatorname{Rec}_{\mathrm{av}} / \mathrm{D}_{\mathrm{n} 50}=5$ with damage up to $\mathrm{S}_{\mathrm{d}}=9-12$. This is well in the range of rock slope stability, see Van der Meer (1988). In Test 2 the rock below swl was 
placed a little more randomly, resulting in a slightly more damage and recession compared to Test 1 . The rock used in Test 3 was slightly larger and more elongated and placed with good interlocking above swl. This resulted in hardy increase in damage and recession for the overload situations.

Table 2. Recession and damage results of 3 tests on Icelandic-type berm breakwater.

\begin{tabular}{|c|c|c|c|c|c|c|c|}
\hline & $H_{s} / \Delta D_{n 50}$ & $s_{\text {op }}$ & $\mathrm{H}_{\mathrm{o}} \mathrm{T}_{\mathrm{om}}$ & $\mathrm{H}_{\mathrm{o}} \mathrm{T}_{\mathrm{op}}$ & $S_{d}$ & $\operatorname{Rec}_{\mathrm{av}}$ & $S_{d}$ Breakwat \\
\hline \multirow[t]{7}{*}{ Test 1} & 0.95 & 0.011 & 24.6 & 28.0 & 0.00 & 0.20 & \\
\hline & 1.50 & 0.013 & 45.7 & 51.0 & 1.39 & 0.29 & \\
\hline & 1.67 & 0.012 & 53.3 & 62.0 & 2.81 & 0.82 & \\
\hline & 1.79 & 0.031 & 47.1 & 43.5 & 4.87 & 1.54 & \\
\hline & 1.75 & 0.015 & 55.6 & 61.1 & 5.73 & 1.69 & \\
\hline & 1.99 & 0.015 & 66.2 & 73.8 & 7.18 & 2.44 & \\
\hline & 2.40 & 0.039 & 55.0 & 60.4 & 8.94 & 3.92 & \\
\hline \multirow[t]{8}{*}{ Test 2} & 0.95 & 0.011 & 24.8 & 28.2 & 0.00 & 0.29 & 0.08 \\
\hline & 1.49 & 0.013 & 45.4 & 50.7 & 2.45 & 0.86 & 0.84 \\
\hline & 1.68 & 0.012 & 48.9 & 63.6 & 5.13 & 2.10 & 2.33 \\
\hline & 1.65 & 0.019 & 43.6 & 48.8 & 5.80 & 2.31 & 2.96 \\
\hline & 1.69 & 0.013 & 51.2 & 62.5 & 6.26 & 2.55 & 3.54 \\
\hline & 1.94 & 0.014 & 64.5 & 71.9 & 9.15 & 4.10 & 4.90 \\
\hline & 2.36 & 0.038 & 53.9 & 59.2 & 11.56 & 5.20 & 7.16 \\
\hline & 1.66 & 0.014 & 52.9 & 58.1 & 11.62 & 5.19 & 7.16 \\
\hline \multirow[t]{9}{*}{ Test 3} & 0.88 & 0.010 & 22.5 & 25.8 & 0.00 & 0.15 & 0.05 \\
\hline & 1.38 & 0.012 & 41.5 & 46.4 & 0.71 & 0.25 & 0.54 \\
\hline & 1.50 & 0.013 & 45.0 & 52.0 & 1.37 & 0.20 & 1.07 \\
\hline & 1.56 & 0.013 & 44.9 & 54.9 & 1.56 & 0.36 & 1.71 \\
\hline & 1.71 & 0.031 & 44.2 & 40.4 & 1.90 & 0.50 & 2.61 \\
\hline & 1.60 & 0.013 & 50.1 & 56.1 & 2.31 & 0.51 & 2.64 \\
\hline & 1.54 & 0.013 & 46.0 & 54.2 & 2.01 & 0.56 & 2.64 \\
\hline & 1.85 & 0.014 & 60.5 & 68.3 & 2.40 & 0.56 & 3.67 \\
\hline & 2.30 & 0.037 & 51.9 & 58.0 & 2.43 & 1.21 & 5.86 \\
\hline
\end{tabular}

\section{Description and comparison of damage $\mathbf{S}_{d}$}

The stability formulae of Van der Meer (1988) include the significant wave height, mean wave period, slope angle and notional permeability. It is also possible to calculate cumulative damage (mainly through BREAKWAT), which makes it possible to simulate the whole test sequence in a test. In the test sequence (see Table 2) sometimes the wave height was kept the same or even lowered, while the wave period was changed. The stability formulae suggest that stability would increase with increasing wave period, as surging or nonbreaking waves are present for a steep slope and with a large notional permeability.

Figure 7 shows the measured damage as a function of the stability number. Damage increases as long as the wave height is increased and the increase in damage is small if tests with similar wave heights have been performed. As explained before, only the overload situation in Test $3\left(\mathrm{H}_{\mathrm{s}} / \Delta \mathrm{D}_{\mathrm{n} 50}=2.3\right)$ showed remarkable stability, due to specific placement of the larger rock. 


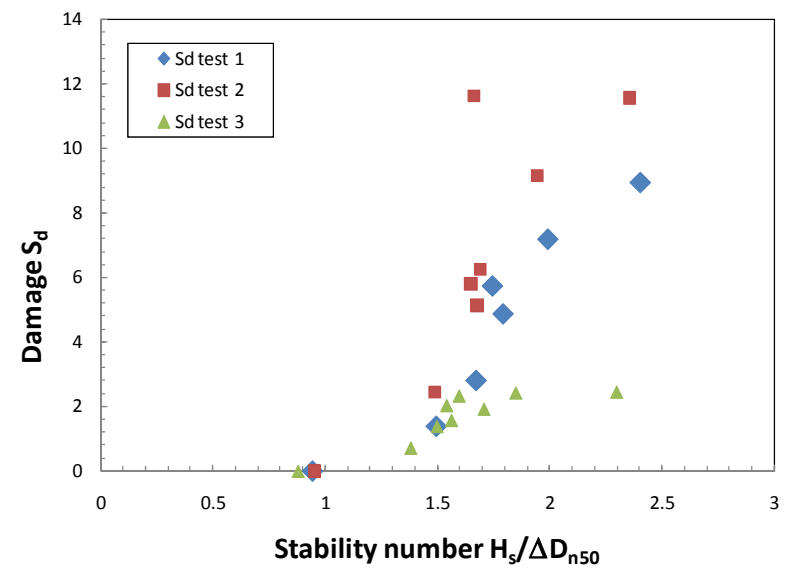

Figure 7. Damage versus stability number, as measured

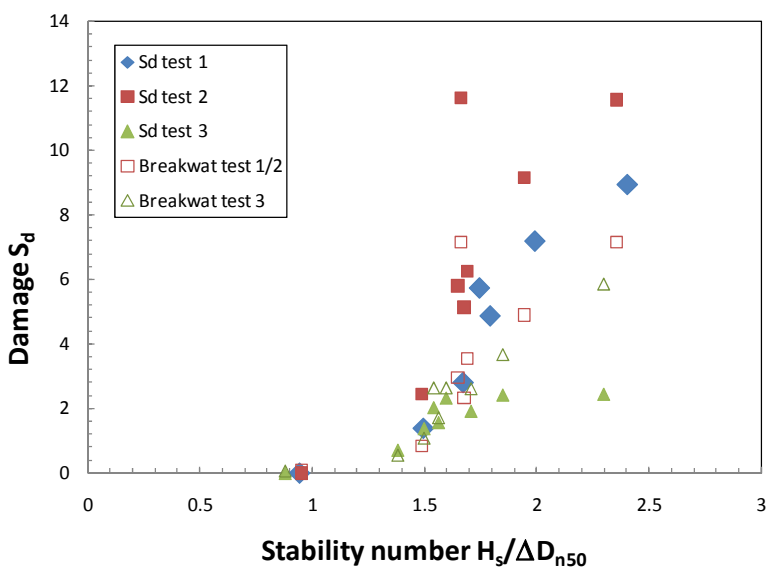

Figure 8. Damage versus stability number, measured and calculated

For Test 2 Figure 7 shows a similar damage of $S_{d}=11.6$ for $H_{s} / \Delta D_{n 50}=2.36$ and 1.66. Actually, in the last test the wave height was lowered (and the wave period increased), but this did not lead to larger damage.

Figure 8 is similar to Figure 7, but now the results of the damage calculations have been included. The cumulative damage was calculated for Test 2 (open squares), which has actually similar conditions as Test 1, and also for Test 3 with different rock size and test conditions (open triangles). Results of calculations depend on the input. The original Van der Meer equations were used through BREAKWAT and cumulative damage was calculated. The berm is very permeable, but the structure is not completely a homogeneous structure. For this reason a notional permeability factor of $\mathrm{P}=0.55$ was used. The seaward slope of the berm breakwater is $1: 1.5$. But it would not give a correct 
comparison if this slope was used in the calculations. The berm breakwater has a horizontal berm and also some horizontal parts below water level (between rock classes I and II and at the toe). The average slope from toe to the crest level was close to 1:2 and therefore this slope angle was used for calculations. Calculated damages are slightly lower for Test 3 than for Tests 1 and 2, which is according to the measurements. It is clear, however, that the berm breakwater in Test 3 showed very good behaviour for the final wave height, better than the prediction of the stability formulae.

Note also that the calculations give similar damage for the last two test series in Test 2, where the wave height was lowered (with an increase in wave period). This is completely according to the measurements, although the damage in average was a little larger in the tests than predicted by the stability formulae.

It can be concluded that the stability formulae for rock slopes in average give a fairly good prediction of the damage at the seaward side of a statically stable Icelandic-type of berm breakwater. The measurements also confirm the stability formulae in the sense that a larger wave period does not really increase damage. Wave height seems to be more important than wave period.

\section{Detailed analysis of recession $\operatorname{Rec}_{\mathrm{av}}$}

Figures 9 and 10 show the development of the average recession, as defined in Figure 6, for the three tests. In Figure 9 the recession is given versus $\mathrm{H}_{\mathrm{o}} \mathrm{T}_{\mathrm{op}}$, which is comparable with Figure 3. Figure 10 uses $H_{s} / \Delta D_{n 50}$ instead of $H_{o} T_{o p}$, and is more comparable with Figure 7.

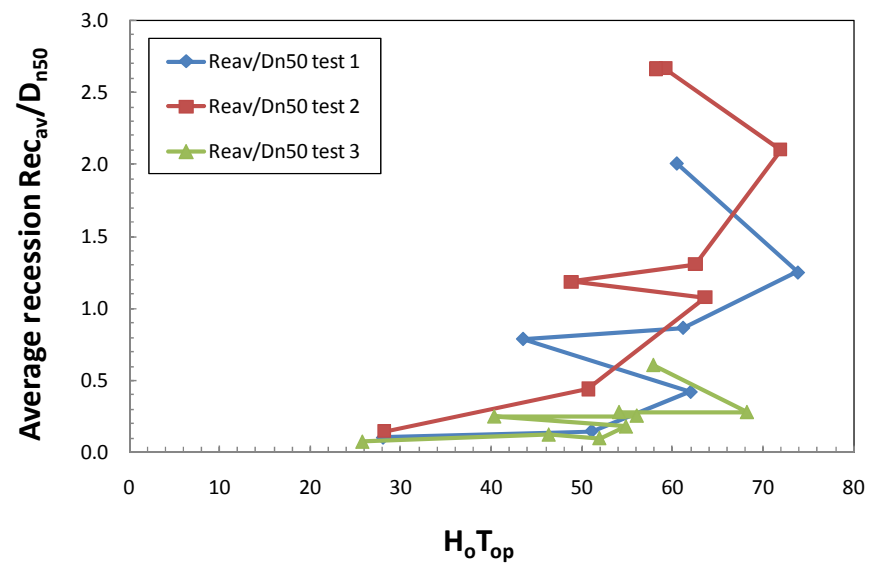

Figure 9. Average recession $\operatorname{Rec}_{a v}$ versus $\mathrm{H}_{\mathrm{o}} \mathrm{T}_{\text {op. }}$

The data points have been connected by lines as this shows better the sequence of the test series in the test. It clearly shows in Figure 9 where sometimes the $\mathrm{H}_{\mathrm{o}} \mathrm{T}_{\mathrm{op}}$ condition was lowered (similar or even larger wave height, but with smaller wave period). If the use of $\mathrm{H}_{\mathrm{o}} \mathrm{T}_{\mathrm{op}}$ would be correct, then a significantly lower $\mathrm{H}_{\mathrm{o}} \mathrm{T}_{\mathrm{op}}$ value should not lead to significant increase of recession. All tests, however, show that recession increases, even with a much lower $\mathrm{H}_{\mathrm{o}} \mathrm{T}_{\mathrm{op}}$ value. 
That is different in Figure 10, where damage increases if $H_{s} / \Delta D_{n 50}$ increases and where damage remains the same if the wave height is reduced. Figure 10 shows a similar behaviour as for the damage in Figure 7. Again it must be concluded that the wave period has hardly any effect on recession and that the wave height is the governing parameter.

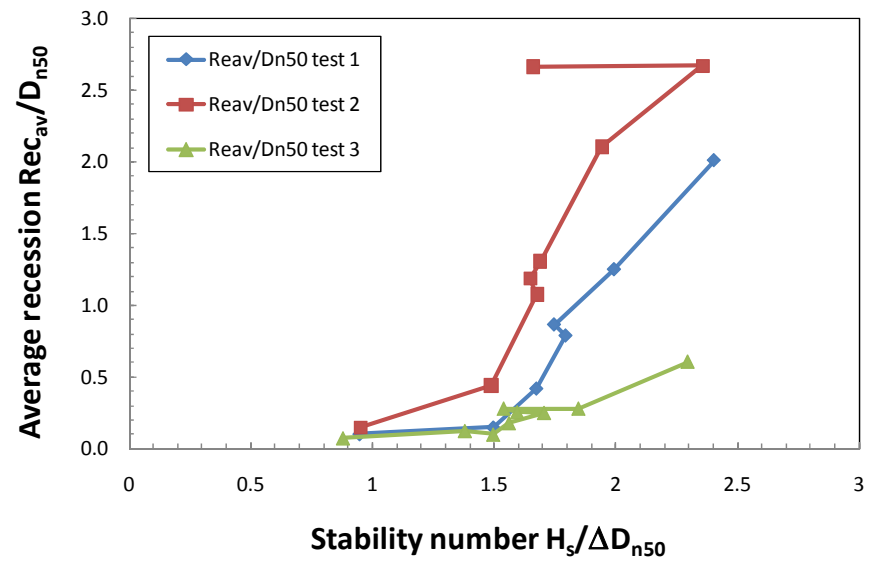

Figure 10. Average recession $\operatorname{Rec}_{\mathrm{av}}$ versus $H_{s} / \Delta D_{n 50}$

It does not mean that the parameter $\mathrm{H}_{\mathrm{o}} \mathrm{T}_{\mathrm{op}}$ is not a good parameter to describe recession or reshaping. The parameter was developed for dynamically stable structures like gravel and cobble beaches, see Van der Meer (1988), and also performs well for really reshaping berm breakwaters with $H_{s} / \Delta D_{n 50}$ around 3 . But start of damage or recession describes more statically stable rock slopes (specifically almost homogeneous structures) and here stability and recession are not really influenced by the wave period.

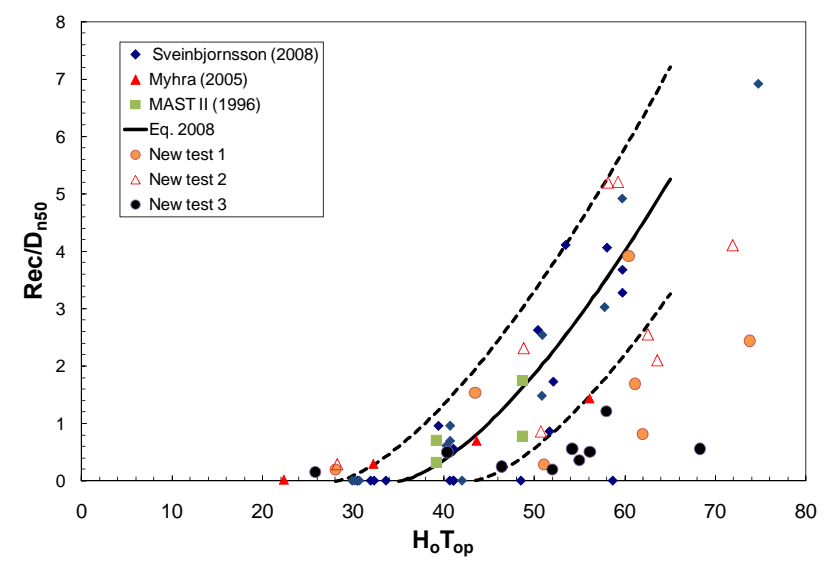

Figure 11. Average recession versus $H_{\circ} T_{o p}$ and data of Sigurdarson et al. (2008). 
Figure 3, taken from Sigurdarson et al. (2008), shows three data sets with Equation 2 as prediction formula. Figure 11 shows the same data, but now with the data of the new tests. As in many test series long wave periods were applied, most of the tests are on the right side of the prediction curve and far outside the $90 \%$ confidence band. As concluded above, it is not a good way to include the wave period for start of recession, comparable to statically stable rock slopes.

Figure 12 shows the average recession versus the stability number $H_{s} / \Delta D_{n 50}$. The results of Test 2 fall exactly within the earlier data, Test 1 shows a little more reshaping and Test 3 , for the final wave height, a little lower. The points of Sveinbjornsson (2008) with $\operatorname{Rec}=0$ are mainly due to inaccuracy as only one profile was measured, not ten as in the latest tests.

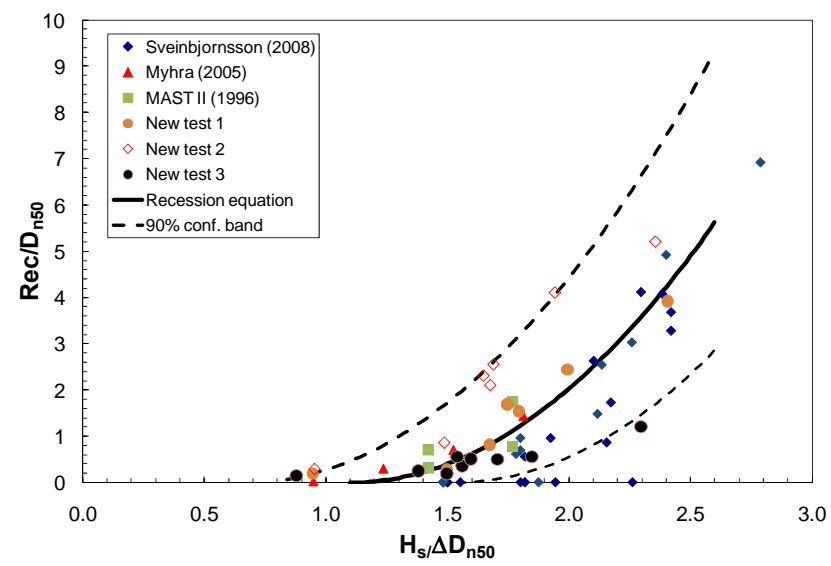

Figure 12. Average recession $\operatorname{Rec}_{a v}$ versus $H_{s} / \Delta D_{n 50}$, with data from Sigurdarson et al. (2008) and with a new prediction formula.

A formula that fits closely to the majority of the data points in Figure 12 is given by:

with:

$$
\operatorname{Rec}_{\mathrm{av}} / \mathrm{D}_{\mathrm{n} 50}=2.5\left(\mathrm{H}_{\mathrm{s}} / \Delta \mathrm{D}_{\mathrm{n} 50}-\mathrm{Sc}\right)^{2}
$$

and:

$$
\operatorname{Rec}_{\mathrm{av}} / \mathrm{D}_{\mathrm{n} 50}=0 \text { for } \mathrm{H}_{\mathrm{s}} / \Delta \mathrm{D}_{\mathrm{n} 50}<\mathrm{Sc}
$$

The formula shows that for a statically stable Icelandic-type berm breakwater with a design value of $\mathrm{H}_{\mathrm{s}} / \Delta \mathrm{D}_{\mathrm{n} 50}=1.5$ the expected recession is not more than about half a stone diameter. For $\mathrm{H}_{\mathrm{s}} / \Delta \mathrm{D}_{\mathrm{n} 50}=2.0$ this may increase to 1.5 to 3 stone diameters, depending on how accurate the rock above swl has been placed.

\section{ALTERNATIVES FOR LARGE ROCK}

The berm of the Icelandic-type berm breakwater is protected with large rock and for large design wave height this can be up to 20 to $35 \mathrm{t}$. The aim is usually to 
quarry as large stones as possible and in required quantities for the project. Reliable quarry yield prediction is a part of the design process. It should be stated that one has to define the right blasting strategy in order to get these large rocks. It has proven feasible in many projects in Iceland and Norway, but not yet in many countries. So, there is a construction risk if these large rock classes have been designed for. What measures are available to reduce this risk if the quarry does not yield large armour stone?

Normally, the Icelandic-type berm breakwater is designed with a front slope of 1:1.5. A flatter front slope is more stable and may require smaller rock. This option has been tested with a slope of 1:2.5 with a maximum armour stone weight of $22 \mathrm{t}$ compared to $35 \mathrm{t}$ for a front slope of 1:1.5. Tests showed similar recession and stability.

Another alternative is to replace the large rock class with concrete elements like cubes. In this case the very porous berm below the cubes is still present and the structure is different to a conventional berm shaped structure with cubes, where under layers are used instead the large rock. This option has also been tested and showed good stability.

\section{CONCLUSIONS}

Statically stable Icelandic type of berm breakwaters, with stability design values roughly between $\mathrm{H}_{\mathrm{s}} / \Delta \mathrm{D}_{\mathrm{n} 50}=1.5-2.0$, can be compared to statically stable (homogeneous) rock slopes. Damage $S_{d}$ and average recession $\operatorname{Rec}_{a v}$ show similar behaviour and are much more depending on wave height than on wave period. This is also what the stability formulae of Van der Meer (1988) predict. Calculated damages compare well with measured ones. A new prediction formula has been developed for recession for this type of berm breakwaters, which uses the stability number $\mathrm{H}_{\mathrm{s}} / \Delta \mathrm{D}_{\mathrm{n} 50}$ and not the dimensionless wave height-wave period parameter $\mathrm{H}_{0} \mathrm{~T}_{\text {op }}$.

It is very important that damage as well as recession is measured in an accurate way and that can be done by taking 10 profiles and analyze the average. Measurements with one to only three profiles are not accurate enough and are probably the reason for large scatter in earlier work like PIANC (2003).

\section{REFERENCES}

MAST II, 1996. Influence of Permeability and Stone Gradation. MAST II - Berm breakwater structures. Contract MAS2-CT94-0087.

MAST II, 1997. Berm breakwater structures. Final Report MAST-Contract MAS2-CT94-0087.

Myhra, H., 2005. Berm breakwaters. Influence of construction method and storm duration on stability. Ice ride-up. MSc-thesis NTNU.

PIANC, 2003. State-of-the-Art of Designing and Constructing Berm Breakwaters. WG40.

Sigurdarson, S., J.W. van der Meer, A. Torum and R. Tomasicchio, 2008. Berm recession of the Icelandic-type berm breakwater. ASCE, Proc. ICCE 2008, Hamburg. pp. 3311-3323.

Sveinbjörnsson, P.I. , 2008. Stability of Icelandic type Berm Breakwaters. MSc-thesis TU Delft.

Van der Meer, J.W., 1988. Rock slopes and gravel beaches under wave attack. Doctoral thesis, Delft University of Technology. Also Delft Hydraulics Publication no. 396. 
KEYWORDS - CSt2011

Abstract acceptance number: $\mathrm{p} 0112$

FRONT SLOPE STABILITY OF THE ICELANDIC-TYPE BERM

BREAKWATER

$1^{\text {st }}$ Author: Sigurdarson, Sigurdur

$2^{\text {nd }}$ Author: van der Meer, Jentsje

Breakwaters

Berm Breakwaters

Coastal structures

Icelandic-type

Recession

Stable berm breakwater 